\title{
Pyrolysis of palm empty fruit bunch: Yields and analysis of bio- oil
}

\author{
Bachrun Sutrisno and Arif Hidayat* \\ Chemical Engineering Department, Universitas Islam Indonesia, Indonesia
}

\begin{abstract}
The palm oil industry is currently growing rapidly and generating large amounts of biomass waste that is not utilized properly. Palm empty fruit bunch (PEFB), by product of palm oil industry is considered as a promising alternative and renewable energy source that can be converted to a liquid product by pyrolysis process. In this work, pyrolysis of PEFB was studied to produce bio-oil. Pyrolysis experiments were carried out in a bench scale tubular furnace reactor. The effects of pyrolysis temperatures $\left(400-600{ }^{\circ} \mathrm{C}\right)$ at heating rate of $10{ }^{\circ} \mathrm{C} / \mathrm{min}$ to optimize the pyrolysis process for maximum liquid yield were investigated. The characteristics of bio-oil were analyzed using FTIR and GC-MS. The results showed that the maximum biooil yield was 44.5 wt. $\%$ of the product at $450{ }^{\circ} \mathrm{C}$. The bio-oil products were mainly composed of acids, aldehydes, ketones, alcohols, phenols, and oligomers. The chemical characterization showed that the bio-oil obtained from PEFB may be potentially valuable as a fuel and chemical feedstock.
\end{abstract}

\section{Introduction}

The problems associated with the fulfillment of energy are the search for feedstock that do not compete with food needs. Biomass, such as agricultural and forest residues, low grade plants, and municipal solid wastes, have a great potential to replace the fossil fuels. Biomass can generally be defined as any hydrocarbon material which mainly consists of carbon, hydrogen, oxygen and nitrogen. Sulfur is also present in less proportion. Some biomass types also carry significant proportions of inorganic species. Utilization of biomass as energy feedstock has attracted attention in recent years. Biomass can be converted to energy by thermochemical processes, such as pyrolysis, gasification and combustion [1].

Pyrolysis is a thermal decomposition process of organic matter that occurs in the absence of oxygen or air. Pyrolysis can directly produce biofuel from biomass which can be readily stored or transported. This process is conducted at moderate temperature, between $400-800{ }^{\circ} \mathrm{C}$. Product of pyrolysis can be divided into three phase: solid, liquid and gas. The solid product or char is useful as a renewable fuel or other applications such as metallurgical and leisure industries, soil amender and the production of activated carbon and electrodes. The gaseous products mainly consist of hydrogen, carbon dioxide, carbon monoxide, ethane, propane and methane which have a low to medium heating value. The gaseous products contain sufficient energy to supply the energy requirements of a pyrolysis process. Bio-oil is the liquid product of pyrolysis process. Bio-oil is a high density oxygenated liquid that can be used as a substitute for liquid fossil fuels in some applications. It can be burned in diesel engines, turbines or boilers.
Pyrolysis can be classified on the basis of heating rate i.e. slow, fast and flash pyrolysis. Slow pyrolysis is characterized by lengthy solids and gas residence times, and slow heating rates. During slow pyrolysis, tar and char are released as main products. In fast pyrolysis process, feedstock is rapidly heated to temperatures of 650 to $1000{ }^{\circ} \mathrm{C}$ depending on the desired amount of biooil or gas products. Flash pyrolysis occurs at rapid heating rates and moderate temperatures between 400 and $600{ }^{\circ} \mathrm{C}$. However, vapor residence time of this process is less than $2 \mathrm{~s}$. Flash pyrolysis produces fewer amounts of gas and tar when compared to slow pyrolysis.

Pyrolysis has been applied to various biomass such as coffee grounds [2], waste tea [3], sugarcane bagasse [4], corn cob, wheat straw, rice straw and rice husk [5], coconut shell [6], oil palm trunk [7], palm kernel shell [8], saw dust [9], aquatic biomass [10] and rubber seed shell and kernel [11]. Palm empty fruit bunch (PEFB) from an oil palm plantation is one of the potential biomass to produce biofuels due to its abundant supply and easy to handle. PEFB is a solid residue of fresh fruit bunch which produced after oil extraction at palm oil mills. On an average, every ton of palm oil produced from a fresh fruit bunch approximately $1 \mathrm{t}$ of PEFBs is generated. Based on Indonesia's palm oil production of 31.5 million tons in 2014, the total PEFB generated from the palm oil industry is around 31.5 million tons. This huge amount of PEFB, if not handled properly, would evoke environmental problems. Composting and incineration are traditional methods which commonly applied to solve these environmental issues. PEFB is chemically composed of cellulose (up to $65.0 \%$ ), hemicellulose (up to $33.52 \%$ ), lignin (up to $30.45 \%$ ) and only slightly of other organics. Cellulose, hemicellulose and lignin are lignocellulose

\footnotetext{
Corresponding author: arif.hidayat@uii.ac.id
} 
components. Lignocellulose components have potential to be utilized as energy source via pyrolysis process. The product distribution of the bio-oil depends on the lignocellulosic composition of the biomass [12]. The decomposition of hemicellulose occurred at $220-315^{\circ} \mathrm{C}$. Cellulose decomposed in the temperature range of 314 $400{ }^{\circ} \mathrm{C}$. The decomposition of lignin took place in a wide range of temperature from 160 to $900{ }^{\circ} \mathrm{C}$, generating highest solid residue $(40 \%)$.

The objectives of this works are: (i) investigate the effect of pyrolysis temperature on product yields, and (ii) characterize liquid product obtained under optimum pyrolysis conditions. The experiments have been carried out at temperatures of 400,450 , and $500{ }^{\circ} \mathrm{C}$ in nitrogen atmosphere. The bio-oil products have been characterized using Fourier Transform-Infrared Spectroscopy (FT-IR) and Gas Chromatography-Mass Spectrometry (GC-MS).

\section{Experimental}

\subsection{Materials}

Palm empty fruit bunches (PEFB) was obtained from Oil Palm plantation in Kalimantan Tengah province, Indonesia The pretreatment process, the material were processed by cutting to small size and then dried at 105 ${ }^{\circ} \mathrm{C}$ for 24 hours. The dried PEFB was grinded to and sieved to $0.5-1.0 \mathrm{~m}$ and then stored. The moisture content of the feedstock was also measured to ensure that it was less than $10 \%$ on a dry feed basis.

\subsection{Pyrolysis Experiments}

The pyrolysis experiments were performed in a stainless steel fixed bed reactor under atmospheric pressure using a batch operation. The reactor was placed into an electrically heated tubular furnace. The reactor was controlled by a thermocouple. In a pyrolysis experiment, a quantity of $10 \mathrm{~g}$ of PEFB was loaded in the reactor. Then, the reactor temperature was increased at a heating rate of $10{ }^{\circ} \mathrm{C} \mathrm{min} / \mathrm{K}$ up to $400{ }^{\circ} \mathrm{C}$ and held at this temperature for $1 \mathrm{~h}$. During heating, the nitrogen $\left(\mathrm{N}_{2}\right)$ gas was flowed into the reactor at the rate of $200 \mathrm{~mL} / \mathrm{min}$ from the bottom. The gases formed from the pyrolysis flows out along with $\mathrm{N}_{2}$ gas from the top of the reactor. The gas was passed through two condensers. The condenser was cooled with the flow of tap water. The liquid products from the condenser and second condenser were collected in conical flasks fitted to the condensers. The bio-oil obtained under experimental conditions that gave maximum oil yield was used for characterization. The chemical composition of bio-oil was analyzed using gas chromatography-mass spectrometry (GC-MS). The functional groups of bio-oil were characterized by using Fourier transform infrared spectroscopy (FTIR) instrument. The effect of temperature was investigated by carrying out the pyrolysis experiments over the temperature range of 400 to $500{ }^{\circ} \mathrm{C}$.

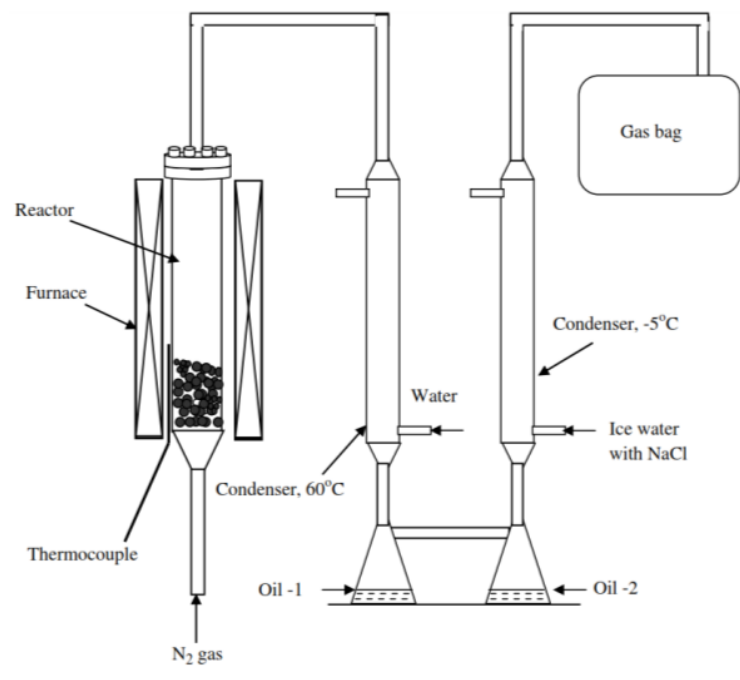

Fig. 1. Pyrolysis Experiments Apparatus.

Where $X_{F}$ is the FFA conversion, $A V_{l}$ is the initial acid value of the mixture and $A V_{2}$ is the acid value of mixture after reaction.

\section{Results and Discussion}

\subsection{The effects of pyrolysis temperatures on the product yields}

Figure 2 shows the bio-oil yields from the pyrolysis of the PEFB with heating rates of 10 and $30{ }^{\circ} \mathrm{C} / \mathrm{min}$ in relation to final pyrolysis temperatures 400,450 , and $500{ }^{\circ} \mathrm{C}$ under nitrogen flow. For the heating rate of $10{ }^{\circ} \mathrm{C} / \mathrm{min}$, the biooil yield increased from 23.5 to $25.1 \%$ as the pyrolysis temperature increase from 400 to $450{ }^{\circ} \mathrm{C}$. The highest biooil yield of $28.3 \mathrm{wt}$. \% was obtained at the final pyrolysis temperature of $500{ }^{\circ} \mathrm{C}$. At the heating rates of $30{ }^{\circ} \mathrm{C} / \mathrm{min}$, the bio-oil yields were $23.40 \%$ and $26.1 \%$, at 400 and 450 ${ }^{\circ} \mathrm{C}$. The bio-oil yield increased to $28.9 \%$ at the final pyrolysis temperature of $500{ }^{\circ} \mathrm{C}$. Increasing the pyrolysis temperature and heating rate increased the bio-oil yield. It was known that the heavy-molecular-weight compounds of pyrolysis vapors become active at high temperature. At high temperatures secondary tar destruction may cause a decrease in the oil yield or increase in the gas yield. The gas product yield increased with pyrolysis temperature.

As shown in Figure 2, as the pyrolysis temperature increased from 400 to $450{ }^{\circ} \mathrm{C}$, the char yields decreased from $33 \%$ to $29.5 \%$ and from $34 \%$ to $30.5 \%$ at heating rates of $10{ }^{\circ} \mathrm{C} / \mathrm{min}$ and $30{ }^{\circ} \mathrm{C} / \mathrm{min}$, respectively. At the final pyrolysis temperature of $500{ }^{\circ} \mathrm{C}$, the char yields decrease to $26.5 \%$ and $28 \%$ when heating rate were 10 and $30{ }^{\circ} \mathrm{C}$, respectively. Higher char yields were obtained for lower heating rates over the entire temperature range. These higher yields may be related to the rapid heating rate, which promotes the fast depolymerisation of the solid material to primary volatiles, while at the lower heating rate, dehydration to more stable anhydrocellulose is limited and very slow. The char yields always decreased with increasing final pyrolysis temperature and heating rate, because the decomposition of the wood or secondary 
decomposition of the char leads to higher conversion with increasing final temperatures.

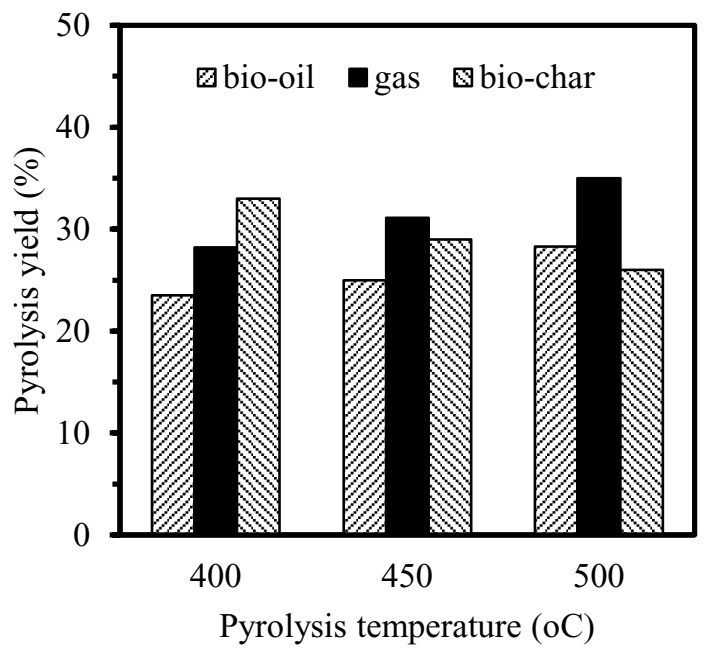

Fig. 2. Effect of final pyrolysis temperature on product yields at a heating rate of $10^{\circ} \mathrm{C} / \mathrm{min}$.

The gas product yields consistently increased with increasing pyrolysis temperature. When the pyrolysis temperature was increased from 400 to $450{ }^{\circ} \mathrm{C}$, the gas yields increased from $28.5 \%$ to $31.5 \%$ and from $29 \%$ to $31.5 \%$ at heating rates of $10{ }^{\circ} \mathrm{C} / \mathrm{min}$ and $30{ }^{\circ} \mathrm{C} / \mathrm{min}$, respectively. At the pyrolysis temperature of $500{ }^{\circ} \mathrm{C}$, the gas yields were $34 \%$ at $10{ }^{\circ} \mathrm{C} / \mathrm{min}$ and $35.5 \%$ at 30 ${ }^{\circ} \mathrm{C} / \mathrm{min}$. The increase in the gaseous product is thought to be predominantly due to the secondary cracking of the pyrolysis vapours at higher temperatures. However, the secondary decomposition of the char at higher temperatures may also generate non-condensable gaseous products. The increase in gas products is thought to occur predominantly due to secondary cracking of the pyrolysis vapours at higher temperatures. However, secondary decompositions of the char at higher temperatures may also give non-condensable gas products.

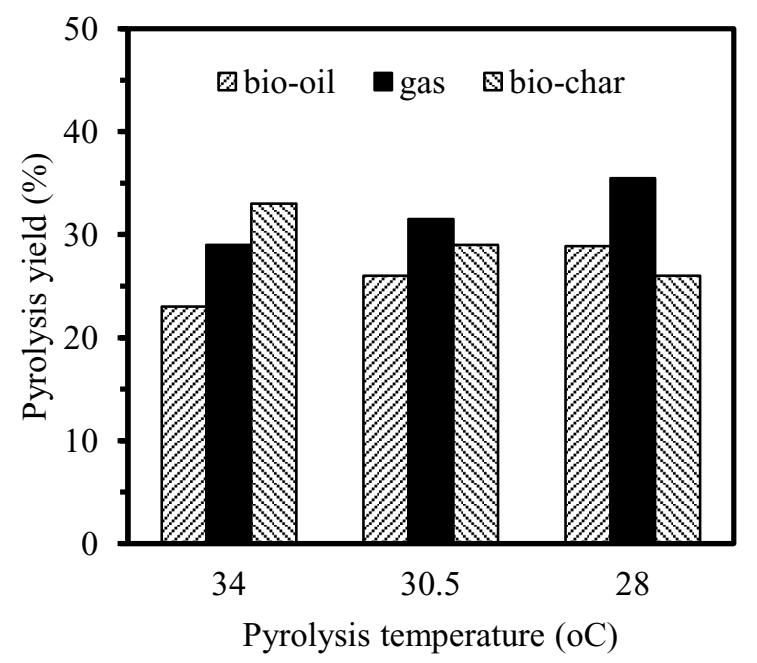

Fig. 3. Effect of pyrolysis temperature on product yields at a heating rate of $30^{\circ} \mathrm{C} / \mathrm{min}$.

\subsection{Chemical Composition}

FT-IR spectra identify functional groups in bio-oils. FTIR spectra are shown in Figure 4. The spectra data showed that alcohol, ketone, ester and carboxylic acid groups are also major oxygen functions present in the bio-oil. The presence of $\mathrm{O}-\mathrm{H}$ vibrations between 3050 and $3600 \mathrm{~cm}^{-1}$ together with the presence of $\mathrm{C}-\mathrm{O}$ stretching vibrations between 1650 and $1850 \mathrm{~cm}^{-1}$ indicates the presence of carboxylic acids and their derivatives. The presence of the C-O stretching vibrations with absorbance between 1650 and $1850 \mathrm{~cm}^{-1}$ may also indicate the presence of the presence of ketone, quinone, and aldehyde groups. The presence of aromatic compounds is confirmed by the aromatic $\mathrm{C}=\mathrm{C}$ stretching vibrations between 1460 and $1455 \mathrm{~cm}^{-1}$. The existence of a $\mathrm{C}-\mathrm{O}$ stretch within 1075 $1020 \mathrm{~cm}^{-1}$ indicates the presence of primary, secondary and tertiary alcohols, phenols, and/or esters. A presence of alcohols and esters in bio-oil are confirmed by the peak appearing between 950 and $1300 \mathrm{~cm}^{-1}$. Bio-oil is a complex mixture, containing mostly aliphatic and aromatic compounds. The presence of hydrocarbon groups indicates that bio-oil has the potential to be used as a fuel or a source of chemicals.

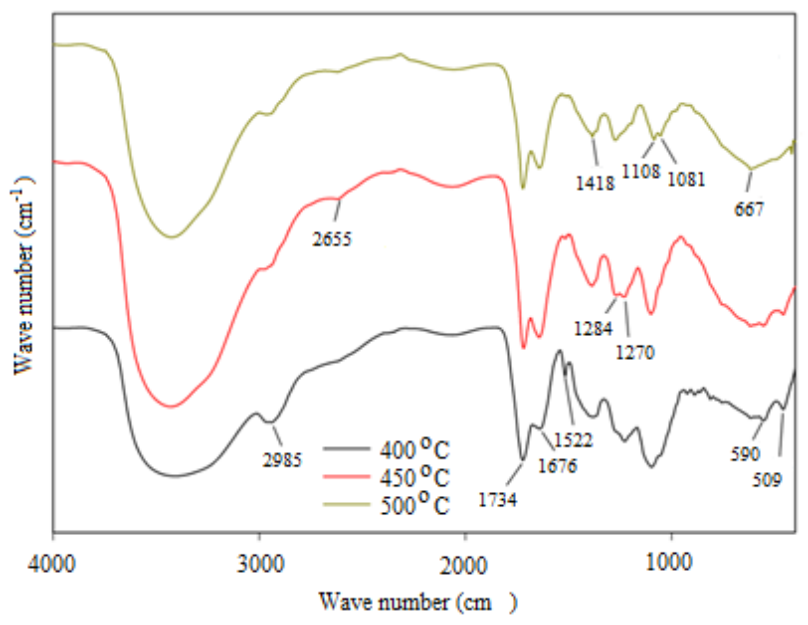

Fig. 4. FT-IR spectra analysis of bio-oil.

GC-MS analysis was carried out in order to get the nature and type of organic compounds in the bio-oil. In general bio-oils are mainly composed of aromatic, aliphatics, aldehydes, and phenolic compounds. Phenols and derivatives are primarily form by decomposition of lignin unit of biomass and the esters, aldehydes, alcohols and ketons are formed by degradation of cellulose and hemicellulose fraction of biomass. Identified compounds can be divided into four different classes of monoaromatics, aliphatics, oxygenated compounds and polyaromatic compounds. Monoaromatic compounds include toluene, furans, phenols, benzene and their derivatives. Aliphatics are mainly consisting of alkanes and alkenes and their derivatives. Oxygenated compounds composed of aldehydes, ketones, carboxylic acid and esters. Table 1 lists the possible compounds identified by the MS search libraries of the bio-oil. The main compounds identified from pyrolysis of PEFB phenolic derivatives and esters. The GC-MS analyzed result shows 
that 3-methyl- phenol, 3-ethyl-phenol, 2,6-dimethoxyphenol, 4-Allyl-2,6-dimethoxyphenol, and phenol were the main phenolic products in the bio-oils. Table 1 also illustrates that there are several esters compounds such as 1-Pentadecene, n-Dodecane, Hexadecanoic acid, Palmitic acid, 9-Octadecenoic acid methyl ester.

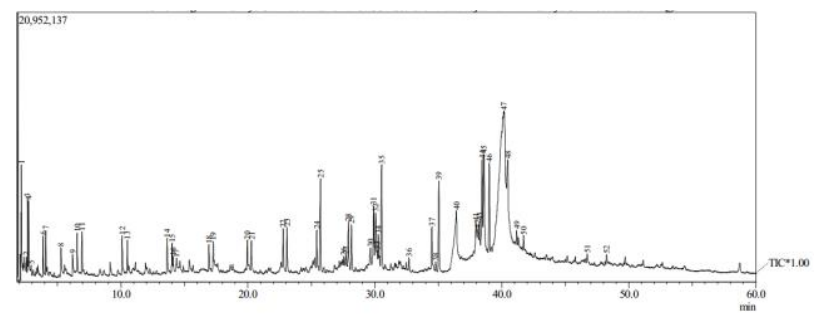

Fig. 4. GC/MS chromatogram of bio-oil from PEFB pyrolysis.

Table 1. Rate constant at different temperatures.

\begin{tabular}{|c|c|c|}
\hline $\begin{array}{c}\text { Retention } \\
\text { Time }\end{array}$ & $\begin{array}{c}\text { Compounds identified in bio- } \\
\text { oil }\end{array}$ & Area, $\%$ \\
\hline 9,708 & 1,2,3-Trimethylbenzene & 1,34 \\
\hline 10,097 & Phenol & 28,99 \\
\hline 12,554 & o-Cresol & 5,44 \\
\hline 12,953 & Guaiacol & 4,93 \\
\hline 13,428 & 3-methyl- phenol & 5,69 \\
\hline 16,396 & 3-ethyl-phenol & 5,08 \\
\hline 19,026 & $\begin{array}{l}\text { 1,4-dimethoxy-2-methyl- } \\
\text { benzene }\end{array}$ & 2,19 \\
\hline 20,978 & 2,6-dimethoxy-phenol & 5,72 \\
\hline 29,826 & 4-Allyl-2,6-dimethoxyphenol & 2,94 \\
\hline 25,412 & 1-Pentadecene & 1,24 \\
\hline 25,682 & n-Dodecane & 3,66 \\
\hline 35,032 & Hexadecanoic acid & 4,58 \\
\hline 36,336 & Palmitic acid & 9,8 \\
\hline 38,392 & $\begin{array}{l}\text { 9-Octadecenoic acid methyl } \\
\text { ester }\end{array}$ & 1,89 \\
\hline 38,950 & Octadecanoic acid methyl ester & 0,85 \\
\hline
\end{tabular}

\section{Conclusions}

In this study, pyrolysis experiments of PEFB were conducted in a fix-bed reactor. The effects of the pyrolysis temperature on the bio-oil yield were investigated for the pyrolysis experiment of PEFB. The optimal yield of biooil could be achieved at the pyrolysis temperature of 500 ${ }^{\circ} \mathrm{C}$. Higher $\mathrm{N}_{2}$ flows rates were more favorable for the production of the bio-oil. GC-MS and FT-IR spectra showed presence of phenolic, ketones and nitrogencontaining group in the bio-oils obtained from the PEFB pyrolysis.
The adsorption experiments indicated that modified coal fly ash was effective in removing of Remazol Blue. The percentage removal of dyes increased while the modified fly ash dosage increased. The percentage removal of dyes increased with decreased initial

\section{References}

1. B. Sutrisno and A. Hidayat, Upgrading of bio-oil from the pyrolysis of biomass over the rice husk ash catalysts, IOP Conference Series: Materials Science and Engineering, 162 (1), 012014 (2016)

2. N. Chen, J. Ren, Z. Ye, Q. Xu, J. Liu, and S. Sun. Bioresource Technology, 221, 534-540 (2016)

3. R. Soysa, Y.S. Choi, S.J. Kim, and S.K. Choi. International Journal of Hydrogen Energy, 41 (37), 16436-16443 (2016)

4. G.C. Goncalves, N.C. Pereira, and M.T. Veit. Biomass and Bioenergy, 85, 178-186 (2016)

5. B. Biswas, N. Pandey, Y. Bisht, R. Singh, and T. Bhaskar. Bioresource Technology, 237, 57-63 (2017)

6. I. Ali, H. Bahaitham, and R. Naebulharam. Bioresource Technology, 235, 1-11 (2017)

7. H.A. Oramahi, Wahdina, F. Diba, Nurhaida, and T. Yoshimura. Procedia Environmental Sciences, 28, 769-777 (2015)

8. S.J. Oh, G.G. Choi, and J.S. Kim. Energy, 113, 108115 (2016)

9. J.X. Wang, J.P. Cao, X.Y. Zhao, T.L. Liu, and X.Y.Wei. Journal of Analytical and Applied Pyrolysis, 125, 279-288 (2017)

10. B. Biswas, R. Singh, B.B. Krishna, J. Kumar, and T. Bhaskar. Bioresource Technology, 242, 139-145 (2017)

11. S.N.A.M. Hassan, M.A.M. Ishak, K. Ismail, S.N. Ali, and M.F. Yusop. Energy Procedia, 52, 610-617 (2014)

12. H. Yang, R. Yan, H. Chen, D.H. Lee, and C. Zheng, Fuel, 86, 1781-1788 (2007) 